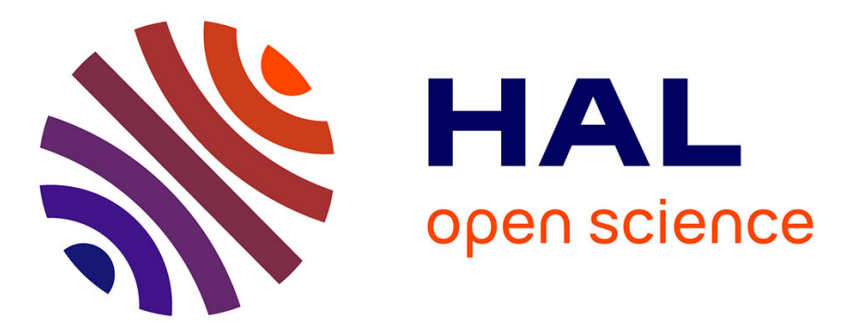

\title{
Investigation on Model Predictive Control of a Five-Phase Permanent Magnet Synchronous Machine under Voltage and Current limits
}

Xavier Kestelyn, Oleg Gomozov, Jerome Buire, Frédéric Colas, Ngac Ky

Nguyen, Eric Semail

\section{To cite this version:}

Xavier Kestelyn, Oleg Gomozov, Jerome Buire, Frédéric Colas, Ngac Ky Nguyen, et al.. Investigation on Model Predictive Control of a Five-Phase Permanent Magnet Synchronous Machine under Voltage and Current limits. ICIT 2015, Mar 2015, SEVILLE, Spain. pp.00. hal-01195725

\section{HAL Id: hal-01195725 \\ https://hal.science/hal-01195725}

Submitted on 8 Sep 2015

HAL is a multi-disciplinary open access archive for the deposit and dissemination of scientific research documents, whether they are published or not. The documents may come from teaching and research institutions in France or abroad, or from public or private research centers.
L'archive ouverte pluridisciplinaire HAL, est destinée au dépôt et à la diffusion de documents scientifiques de niveau recherche, publiés ou non, émanant des établissements d'enseignement et de recherche français ou étrangers, des laboratoires publics ou privés. 


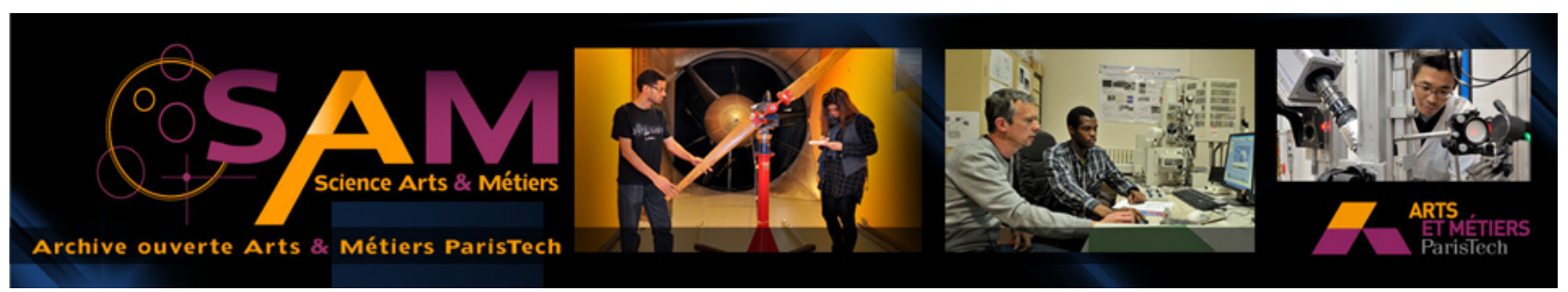

\section{Science Arts \& Métiers (SAM)}

is an open access repository that collects the work of Arts et Métiers ParisTech researchers and makes it freely available over the web where possible.

This is an author-deposited version published in: http://sam.ensam.eu

Handle ID: .http://hdl.handle.net/10985/9946

\section{To cite this version :}

Xavier KESTELYN, Oleg GOMOZOV, Jerome BUIRE, Frédéric COLAS, Ngac Ky NGUYEN, Eric SEMAIL - Investigation on Model Predictive Control of a Five-Phase Permanent Magnet

Synchronous Machine under Voltage and Current limits - In: ICIT 2015, Espagne, 2015-03 - ICIT $2015-2015$ 


\title{
Investigation on Model Predictive Control of a Five-Phase Permanent Magnet Synchronous Machine under Voltage and Current limits
}

\author{
Xavier Kestelyn, Oleg Gomozov, Jérôme Buire, Frédéric Colas, Ngac Ky Nguyen and Eric Semail \\ L2EP, Laboratoire d'Electrotechnique et d'Electronique de Puissance de Lille \\ Ecole Nationale Supérieure d'Arts et Métiers (ENSAM) - Campus of Lille \\ 8 bd Louis XIV F-59046, Lille, France \\ Email: Xavier.Kestelyn@ensam.eu
}

\begin{abstract}
The optimal control of electrical drives necessitates to take into account current and voltage limits that are imposed by the power electronics and the electrical machines. Let's cite for example the flux-weakening operation of electrical drives for propulsion. If the control of classical three-phase drives under voltage and current limits are known for a long time, the specific characteristics of multiphase drives open the way to researches on their control under such constraints. This paper aims to explain what are the main differences between three-phase and multiphase drives when they run under voltage and current constraints and try to show what are the scientific and technical problems to be solved. Some first results are given in order to show that Model Predictive Control (MPC) is expected to be a good candidate to answer the proposed challenge.
\end{abstract}

\section{INTRODUCTION}

Compared to classical three-phase drives, multiphase drives (having more than three phases) reduce the electrical stresses on machine and power electronic components and have inherent fault-tolerance capabilities [1], [2]. Such advantages lead to the use of multiphase drives on various applications where voltage and current limits can be reached. As an example, the use of a multiphase drive for the propulsion of an electrical car imposes to control the drive in the flux weakening region (where voltage limits are reached) [3],[4],[5] . Although there are still some researches on advanced control of threephase drives working at their voltage and current limits, the specificity of multiphase drives imposes to develop specific control algorithms.

Electrical drives are mainly composed of electrical machines supplied by Voltage Source Inverter (VSI). The electrical limits that have to be considered when controlling the drive are due to the VSI and the machine itself. The maximum phase peak voltage (voltage limit) comes from the chosen bus voltage and current limits are due to the maximum phase peak current (current limit due to the inverter's switches or the demagnetizing current of the machine) and to the maximum copper losses or RMS phase current (current limit due to the machine). It is considered in this paper that the RMS value never exceeds its maximum. Electrical limits that are considered are then the followings:

$$
\begin{aligned}
v_{\text {phase-to-phase }}(t) & \leq U_{\text {peak-max }} \\
i_{\text {phase }}(t) & \leq I_{\text {peak-max }}
\end{aligned}
$$

Control of electrical drives are classically implemented in multiple $d q$ reference frames (extended Park transformation). For a $n$-phase star-coupled drive, $\frac{n-1}{2} d q$ reference frames are needed. In that case, the $k$ first current harmonics can be correctly tracked in steady-state with the use of simple PI controllers $(k<n)$ [1],[2],[6].

For three-phase drives and considering only the voltage and current fundamentals, only one $d q$ reference frame is used. Peak and RMS phase variables are easily related to $d q$ variables since $\sqrt{x_{d}^{2}+x_{q}^{2}}=\sqrt{3} X_{\text {peak }}=\sqrt{\frac{3}{2}} X_{R M S}$. Optimal control of three-phase drives working at their voltage and current limits is then easy to implement since the control of $d q$ variables ensures the respect of imposed limits. As recalled in [7], below the limits and when the machine has smooth poles, it is sufficient to get a torque equal to its reference $T_{e m}=T_{e m}^{*}$ to set (considering the speed-normalized emf $\epsilon_{q}=\frac{e_{q}}{\Omega}$ ):

$$
\begin{array}{r}
i_{d}^{*}=0 \\
i_{q}^{*}=\frac{T_{e m}^{*}}{\epsilon_{q}}
\end{array}
$$

to ensure an optimal solution (from the copper losses point of view). When the drive works at its limits, it is sufficient to inject a negative current $i_{d}$ to weaken the machine flux in order to respect the imposed voltage limit $V_{\text {peak-max }}$ and to adjust if necessary current $i_{q}$ in order not to exceed the rated current $I_{\text {peak-max }}$. If the machine has salient poles, analytical expressions of $i_{d}^{*}$ and $i_{q}^{*}$ still exist and the optimal control is then easy to implement. It has however to be noticed that the classical approaches are most of the time applied considering the drive in steady-state (electrical and mechanical dynamics are not taken into account).

For multiphase drives the problem is much more complex since it is necessary to control simultaneously multiple sets of $d q$ variables. Under classical assumptions of linear behaviour of the machine and below voltage and current limits, each $d q$ 
set of variables is independent from the other and can then be controlled independently. As proved in [8], for a $n$-phase PMSM with harmonic rank $k$ of EMF $e(t)$ supposed negligible if $k>n$, the optimal $d q$ currents references (from a copper losses point of view) in order to get a torque $T_{e m}=T_{e m}^{*}$ are given by:

$$
i_{q_{k}}^{*}=\frac{\epsilon_{d_{k}}^{*}=0}{\sum_{i=1}^{n} \epsilon_{q i}^{2}} T_{e m}^{*}
$$

However, if voltage and current limits are taken into account, computing a set of $d q$ current references for the generation of an expected torque at a given speed is not only a difficult problem to solve but also, from the authors' knowledge, does not have any analytical solution. The difficulty comes from the fact that it is not possible to compute optimal current references since peak and RMS values of phase variables have no analytical relationships. Indeed, the phase peak value of a variable depends on the peak value of each harmonic $\left(X_{\text {peak }_{k}}=\sqrt{x_{d_{k}}^{2}+x_{q_{k}}^{2}}=\sqrt{2} X_{R M S_{k}}\right)$ but also on their respective phase shifts. When a multiphase drive is subject to voltage and current constraints, simplifications on the expressions of the limits are necessary to get analytical expressions of peak values. One of the most popular assumptions consists in considering that the worst case, when all harmonics are in phase, permanently occurs [9] [10] [11] [12] [13]. In that case, the peak value of a phase variable is easily define by:

$$
X_{\text {peak-simplified }}=\sum_{i=1}^{n} \sqrt{x_{d i}^{2}+x_{q i}^{2}}
$$

It is nothing to say that taking this assumption leads to severe restrictions in the expected performances of the drive.

This paper shows that Model Predictive Control (MPC) is as a good candidate to compute in real-time optimal current references of a PMSM five-phase drive under voltage and current constraints.

\section{Presentation of the Studied DRiVe}

The chosen drive is a prototype that has been developed in the frame of an industrial project. It is composed of a star-coupled synchronous permanent magnet machine with five phases denoted $A, B, C, D$ and $E$. The machine is supplied by a five-leg Voltage Source Inverter (VSI) connected to a DC bus denoted $V_{\text {bus }}$ and controlled with Pulse Width Modulation (PWM). Fig. 1 shows a synoptic of the drive.

Speed $\Omega$ of the machine shaft is estimated via an incremental optical encoder and is controlled by a PI controller which generates the torque reference $T^{*}$. A Model Predicitve Control based current reference generator is used to compute the $d q$ current references. These references are compared to the $d q$ currents which are estimated via an extended inverse Park transformation applied to the phase current measurements. Voltage references for the VSI are generated by the $d q$ current

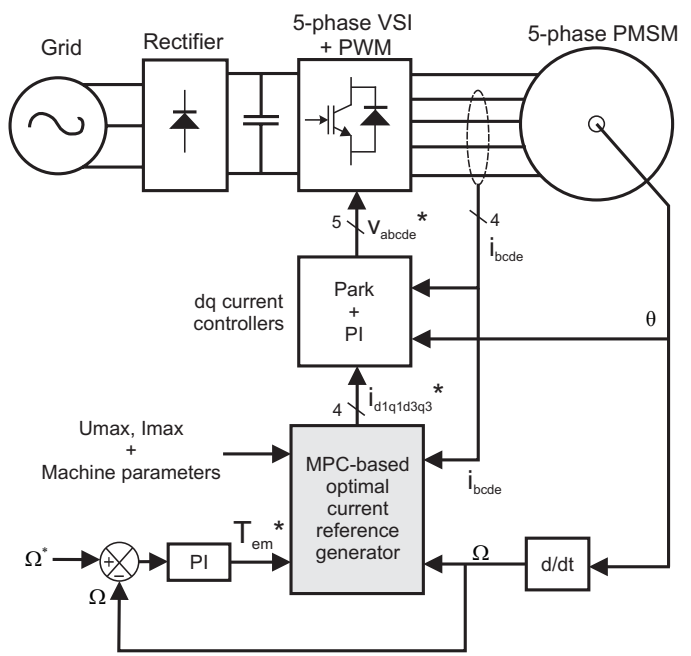

Fig. 1: Synoptic of the studied drive

controls, made with PI controllers, which generate the $d q$ reference voltages.

\section{A. Modelling of the drive}

The model of the machine is written in multiple $d q$ reference frames. Equations (8) to (14) are obtained by using the extended Park transformation $T$ given by (15). The fictitious multimachine concept is used in this paper and makes possible to associate a two-phase fictitious machine to each $d q$ subspace [18]. The first fictitious machine is called the Main Machine and is modelled in the $d q_{1}$ plane. This machine is associated with the fundamental variables of the real machine. The second fictitious machine is called the Secondary Machine and is modelled in the $d q_{3}$ plane. The variables of the Secondary Machine are associated with the third harmonic of the real machine variables. The assumptions that have been used are: 1-The magnetic saturation, the hysteresis effects and the iron losses are not taken into account, 2-Slot effects are neglected, 3-Only harmonic one and three of periodical variables are considered.

$$
\begin{aligned}
v_{1 d} & =R i_{1 d}+L_{1 d} \frac{d i_{1 d}}{d t}-p \Omega L_{1 q} i_{1 q} \\
v_{1 q} & =R i_{1 q}+L_{1 q} \frac{d i_{1 q}}{d t}+p \Omega\left(L_{1 d} i_{1 d}+\sqrt{\frac{5}{2}} \Phi_{1 f}\right) \\
v_{3 d} & =R i_{3 d}+L_{3 d} \frac{d i_{3 d}}{d t}+3 p \Omega L_{3 q} i_{3 q} \\
v_{3 q} & =R i_{3 q}+L_{3 q} \frac{d i_{3 q}}{d t}+3 p \Omega\left(-L_{3 d} i_{3 d}+\sqrt{\frac{5}{2}} \Phi_{3 f}\right) \\
T_{e m 1} & =p\left[\left(L_{1 d}-L_{1 q}\right) i_{1 d} i_{1 q}+\sqrt{\frac{5}{2}} \Phi_{1 f} i_{1 q}\right] \\
T_{e m 3} & =3 p\left[\left(L_{3 d}-L_{3 q}\right) i_{3 d} i_{3 q}+\sqrt{\frac{5}{2}} \Phi_{3 f} i_{3 q}\right]
\end{aligned}
$$




$$
T_{e m}=T_{e m 1}+T_{e m 3}
$$

In equations (8) to (14) appear:

- $v_{1 d}, v_{1 q}, v_{3 d}, v_{3 q}$ and $i_{1 d}, i_{1 q}, i_{3 d}, i_{3 q}$ the $d q_{1}$ and $d q_{3}$ voltages and currents respectively associated with the first and the third harmonic of phase variables

- $R$ the phase resistance

- $L_{1 d}, L_{1 q}, L_{3 d}, L_{3 q}$ the inductances along $d$ and $q$ axis associated with the first and the third harmonic of the air gap flux

- $p$ the pole pair number

- $\Omega$ the speed of the mechanical shaft

- $\Phi_{1 f}$ and $\Phi_{3 f}$ the flux along the $d$ axis created by the permanent magnets respectively associated with the first and the third harmonic of the air gap flux

- $T_{e m 1}$ the electromagnetic torque created by the first harmonic of the air gap flux

- $T_{e m 3}$ the electromagnetic torque created by the third harmonic of the air gap flux

- $T_{e m}$ the total electromagnetic torque

Table I sums up the experimental data of the studied prototype drive developed in the frame of an industrial project.

\section{PRoposed MPC SOLUTION FOR THE REAL-TIME CONTROL OF MULTIPHASE ELECTRICAL DRIVES UNDER VOLTAGE AND CURRENT LIMITS}

\section{A. Existing MPC solutions for the real-time control of multi- phase electrical drives}

Model Predictive Control (MPC) is based on a model of the system that is used to predict the behaviour of the plant in order to choose optimal values for the control variables. One of the main advantage of MPC is its ability to tackle problems involving multi-input multi-output systems that are subject to constraints, such as imposed limits on the state variables. Because of the computational effort required by MPC, its implementation has been for a long time restricted to slow systems. However, the advance in real-time solutions makes now possible to implement MPC for fast systems with shorter time steps, as power electronics and electrical drives, and become an established control technique in that fields [14].

TABLE I: Data of the studied system

\begin{tabular}{|c||c|}
\hline Parameter & Value \\
\hline Resistance $R$ & $9.1 \mathrm{~m} \Omega$ \\
Inductance $L_{d 1}$ & $0.13 \mathrm{mH}$ \\
Inductance $L_{q 1}$ & $0.13 \mathrm{mH}$ \\
Inductance $L_{d 3}$ & $0.051 \mathrm{mH}$ \\
Inductance $L_{q 3}$ & $0.041 \mathrm{mH}$ \\
Flux $\Phi_{1 f}$ & $19.4 \mathrm{mWb}$ \\
Flux $\Phi_{3 f}$ & $0.675 \mathrm{mWb}$ \\
Bus voltage $V_{b u s}$ & $50 \mathrm{~V}$ \\
Maximum peak current per inverter leg $I_{V S I}$ & $125 \mathrm{~A}$ \\
Thermal equivalent RMS current $I_{T H}$ & $64 \mathrm{~A}$ \\
Maximum expected speed $\Omega_{\max }$ & $16000 \mathrm{rpm}$ \\
\hline
\end{tabular}

MPC techniques can be divided in two wide categories. Continuous-control-set MPC (CCS-MPC) is based on an average model of the system to be controlled and generates continuous reference signals. Finite-control-set MPC (FCSMPC) takes advantage of the limited number of switching states available in the power converters for solving the optimization problem using a simple iterative algorithm. The main differences are the way the optimization is performed and how the control actions are applied [15].

MPC researches in the multiphase drive area predominantly relates to the closed-loop current controls. A finite control-set model predictive control (FCS-MPC), which consists in applying at each sampling time the best combination of switching states in order to minimize a cost function, is implemented [16],[17]. The objective is to use FCS-MPC for its ability to offer good transient performances over classical (PI+PWM)based controls. Unfortunately, with FCS-MPC, voltage and current limits are not optimally taken into account in the proposed algorithms.

\section{B. Proposed MPC solution for the real-time control of multi- phase electrical drives}

In this paper, we propose to use a CCS-MPC to generate optimal current references of the drive under voltage and current constraints. Although the developed CCS-MPC generates also the optimal voltage references, it has been preferred to use PI current controls since the CCS-MPC needs a high computation time (around $10 \mathrm{~ms}$ ), which is not acceptable for a safe current control (slowest electrical time constant equal to $4.5 \mathrm{~ms}$ ).

The objective is to get the expected torque along the minimization of the copper losses with respect to fixed maximum peak current and voltage. The problem to be solved can be written as follows:

$\operatorname{minimize}\left(\omega_{i}\left(i_{1 d}^{2}+i_{1 q}^{2}+i_{3 d}^{2}+i_{3 q}^{2}\right)+\omega_{T}\left(T_{e m}^{*}-T_{e m}\right)^{2}\right)$

subject to:

$$
\begin{aligned}
\operatorname{peak}\left(i_{A, B, C, D, E}\right) & \leq I_{V S I} \\
\operatorname{peak}\left(u_{A B, A C, A D, A E}\right) & \leq V_{\text {bus }}
\end{aligned}
$$

the respect of equations (8) to (14)

The proposed optimization problem can be transformed into a linear problem with a quadratic cost function and linear constraints. The interior-point-convex algorithm given by MATLAB (quadprog from the optimization toolbox) has then been chosen to solve the proposed problem.

Equations (8) to (14) are discetized at each sampling instant $k \Delta T$, where $\Delta T$ is the sampling time. The discretized model is used to obtain the first-step predicted phase voltages and currents that are used to compute the cost function and to calculate the peak values that constraint the optimization problem. The predictive model is assumed to be time-invariant across the prediction horizon, which implies that the torque 


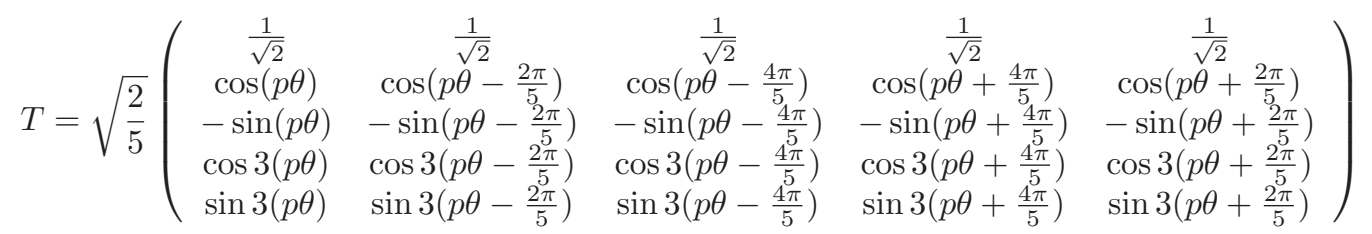

reference $T_{e m}^{*}$ and the speed $\Omega$ remain constant throughout the prediction horizon. The derivative is approximated using a backward Euler method: $\frac{d u(t)}{d t} \rightarrow \frac{u(k+1)-u(k)}{\Delta T}$. Currents at instant $k$ are measured, filtered and transformed in order to predict voltages, currents and torque at instant $k+1$.

To be solved by the MATLAB solver quadprog, the optimization problem has to be written in a matrix form as follows:

$$
\text { minimize }\left(\frac{1}{2} X^{\prime}(k+1) * H * X(k+1)\right)
$$

subject to:

$$
\begin{array}{r}
A(k) * X(k+1) \leq b(k) \\
A_{e q}(k) * X(k+1)=b_{e q}(k)
\end{array}
$$

with

$$
X(k+1)=\left(\begin{array}{c}
i_{1 d}(k+1) \\
i_{1 q}(k+1) \\
i_{3 d}(k+1) \\
i_{3 q}(k+1) \\
v_{1 d}(k+1) \\
v_{1 q}(k+1) \\
v_{3 d}(k+1) \\
v_{3 q}(k+1) \\
T_{e m}^{*}(k)-T_{e m}(k+1)
\end{array}\right)
$$

Matrices $A(k), b(k), A_{e q}(k)$ and $b_{e q}(k)$ are given by (20) to $(24)$.

\section{FIRST RESULTS}

Simulations results have been carried out in order to validate the proposed approach. An average model is considered for the VSI. $U_{\text {peak-max }}=V_{\text {bus }}$ is set to $50 \mathrm{~V}$ and $I_{\text {peak-max }}=I_{V S I}$ to $125 \mathrm{~A}$. The MPC reference generator has a sampling time of $10 \mathrm{~ms}$. The weights $\omega_{i}$ and $\omega_{T}$ define the trade off between the minimization of the copper losses and the tracking of the torque reference. Their values are chosen empirically with $\omega_{i} \ll \omega_{T}$ which allows, while always minimizing copper losses, the best tracking of torque reference when it is inside feasible region and having the torque equal to its maximum value when the reference is infeasible. In this work the following values are used : $\omega_{i}=0.001$ and $\omega_{T}=70$. To avoid numerical problems due to a bad conditioning, it should be noted that the choice of $\omega_{i}$ and $\omega_{T}$ values has to take into account the round-off effects. Too big or too small values are then to be avoided.

The first test consists in verifying the dynamic behaviour of the proposed MPC and its ability of respecting the current limit $\left(i_{\text {phase }}(t) \leq I_{V S I}\right)$. All simulation results are shown in
Figure 2. The initial speed and torque references are set to zero. At $t=0.01 \mathrm{~s}$ the speed is set to $100 \mathrm{rad} / \mathrm{s}$. At $t=0.03 \mathrm{~s}$ the torque reference is set to $25 \mathrm{Nm}$ and at $t=0.06 \mathrm{~s}$ at $75 \mathrm{Nm}$.

The torque plot shows that due to the sampling time of the MPC-based reference generator, there is a delay of $10 \mathrm{~ms}$ between the torque and its reference. If the torque reference of $30 \mathrm{Nm}$ can be tracked by the drive, at $\mathrm{t}=0.07 \mathrm{~s}$, the torque is limited to its maximum value, which is equal to $48.2 \mathrm{Nm}$.

The current plot shows that at $t=0.07 \mathrm{~s}$ the torque is limited because of the current constraint $i_{\text {phase-peak }}=I_{V S I}=125 \mathrm{~A}$. From $t=0.04 \mathrm{~s}$ to $t=0.07 \mathrm{~s}$ the phase shift between first and third current harmonics are opposite in phase in order to get the maximum torque for the minimum copper losses, while from $t=0.07 \mathrm{~s}$ the harmonics are in phase to maximize the peak value of the phase currents. This analysis can also be done by inspecting the $d q$ currents. Since the peak phase-to-phase voltages never reach their limits (set at $50 \mathrm{~V}$ ), the machine is never flux-weakened and $i_{d 1}$ and $i_{d 3}$ are always equal to zero. Before the current limit is reached, $i_{q 1}$ and $i_{q 3}$ are both positive to produce the maximum torque for given copper losses (as stated by (5) and (6)). When the current limit is reached, $i_{q 3}$ becomes negative to makes possible to $i_{q 1}$ to be the greatest as possible. This very particular functioning mode, which is only possible with multiphase drives, can be considered as a "third-harmonic-based torque weakening".

The second test consists in plotting the maximum torque versus speed characteristic (see Figure 3) in order to validate the ability of the MPC-based current reference generator to respect the voltage constraints. The torque reference is set to its maximum $(48.2 \mathrm{Nm})$ and a speed ramp is imposed to the machine. It has to be noticed that the base speed is equal to $1430 \mathrm{rpm}$ and that the limit speed is over $30.000 \mathrm{rpm}$. Since we are looking for the maximum torque available, the peak phase currents are always equal to their limits (set at $125 \mathrm{~A}$ ). Finally, peak phase-to-phase voltages are always inferior or equal to the maximum imposed voltage (50 V in our case).

$d q_{1}$ and $d q_{3}$ currents have very different behaviours depending on the functioning mode. Before the base speed, the machine is not flux-weaken since $i_{d 1}$ and $i_{d 3}$ are all set to zero. It has to be noticed that if $i_{q 1}$ is positive in order to produce a positive torque with the first harmonic of the flux, $i_{q 3}$, associated with the third current harmonic is negative to get the maximum peak value for the phase currents. When the base speed is reached, as for a classical three-phase machine, the first and the third harmonics of the flux are weakened $\left(i_{d 1}<0\right.$ and $\left.i_{d 3}<0\right)$. If $i_{d 1}$ and $i_{q 1}$ are kept respectively positive and negative over the base speed, it is important to note that $i_{d 3}$ and $i_{q 3}$ are adapted in order to maximize 


$$
\begin{aligned}
& H=\operatorname{diag}\left(\omega_{i}, \omega_{i}, \omega_{i}, \omega_{i}, 0,0,0,0, \omega_{T}\right) \\
& A(k)=\left(\begin{array}{ccc}
T_{0 \ldots 2 \pi}(0) & 0 & 0 \\
0 & T_{0 \ldots 2 \pi}(0)-T_{0 \ldots 2 \pi}\left(\frac{2 \pi}{5}\right) & 0 \\
0 & T_{0 \ldots 2 \pi}(0)-T_{0 \ldots 2 \pi}\left(\frac{4 \pi}{5}\right) & 0
\end{array}\right) \quad b(k)=\left(\begin{array}{c}
\vdots \\
I_{\text {peak-max }} \\
V_{\text {bus }} \\
\vdots \\
V_{\text {bus }}
\end{array}\right) \\
& T_{0 \ldots 2 \pi}(\alpha)=\sqrt{\frac{2}{5}}\left(\begin{array}{cccc}
\cos (-\alpha) & -\sin (-\alpha) & \cos 3(-\alpha) & \sin 3(-\alpha) \\
\cos \left(\frac{2 \pi}{h}-\alpha\right) & -\sin \left(\frac{2 \pi}{h}-\alpha\right) & \cos 3\left(\frac{2 \pi}{h}-\alpha\right) & \sin 3\left(\frac{2 \pi}{h}-\alpha\right) \\
\cos \left(2 \frac{2 \pi}{h}-\alpha\right) & -\sin \left(2 \frac{2 \pi}{h}-\alpha\right) & \cos 3\left(2 \frac{2 \pi}{h}-\alpha\right) & \sin 3\left(2 \frac{2 \pi}{h}-\alpha\right) \\
\cos \left(3 \frac{2 \pi}{h}-\alpha\right) & -\sin \left(3 \frac{2 \pi}{h}-\alpha\right) & \cos 3\left(3 \frac{2 \pi}{h}-\alpha\right) & \sin 3\left(3 \frac{2 \pi}{h}-\alpha\right) \\
\cdots & \cdots & \cdots & \cdots \\
\cos (2 \pi-\alpha) & -\sin (2 \pi-\alpha) & \cos 3(2 \pi-\alpha) & \sin 3(2 \pi-\alpha)
\end{array}\right)
\end{aligned}
$$

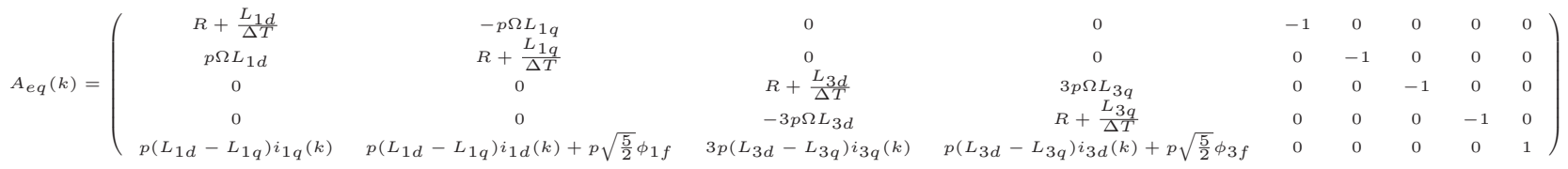

$$
\begin{aligned}
& b_{e q}(k)=\left(\begin{array}{c}
\frac{L_{1 d}}{\Delta T} i_{1 d}(k) \\
\frac{L_{1 q}}{\Delta T} i_{1 q}(k)-p \Omega \sqrt{\frac{5}{2}} \phi_{1 f} \\
\frac{L_{3 d}}{\Delta T} i_{3 d}(k) \\
\frac{L_{3 q}}{\Delta T} i_{3 q}(k)-3 p \Omega \sqrt{\frac{5}{2}} \phi_{3 f} \\
p\left(L_{1 d}-L_{1 q}\right) i_{1 d}(k) i_{1 q}(k)+3 p\left(L_{3 d}-L_{3 q}\right) i_{3 d}(k) i_{3 q}(k)+T^{*}(k)
\end{array}\right)
\end{aligned}
$$

the torque produce by the first harmonic of the flux along respecting the current and voltage limits.

This analysis demonstrates that the optimality of the proposed solution is only possible because amplitudes and phase shifts of the third current and voltage harmonics have been adapted in a specific way for each functioning point.

\section{CONCLUSION}

This paper shows that Model Predicitve Control is a good candidate to optimally control in real-time multiphase drives under voltage and/or current constraints. Future works are in progress in order to implement (with FPGA or mircocontroller systems) the proposed solution on a five-phase prototype drive that has been developed for industrial purposes.

\section{REFERENCES}

[1] E. Levi, R. Bojoi, F. Profumo, H.A. Tolyat and S. Williamson, "Multiphase induction motor drives: a technology status review", Electric Power Application, IET, July 2007, vol. 1, pp. 489-516.

[2] E. Levi, Multiphase Electric Machines for Variable-Speed Applications, IEEE Transactions on Industrial Electronics, Vol. 55, No. 5, May 2008, pp. 1893-1909.

[3] J. Riveros, B. Bogado, J. Prieto, F. Barrero, S. Toral and M. Jones, Multiphase machines in propulsion drives of electric vehicles, $14^{t} \mathrm{~h}$ International Power Electronics and Motion Control Conference (EPE/PEMC), 6-8 Sept. 2010, Ohrid, Republic of Macedonia, pp. T5-201 - T5-206.

[4] A. Baltatanu and M.-L. Florea, Multiphase machines used in electric vehicles propulsion, International Conference on Electronics, Computers and Artificial Intelligence (ECAI), 27-29 June 2013, Pitesti, Romania, pp. 1-6
[5] O. Ojo and H.A. Toliyat, Editorial on the Special Issue on Advanced Control of Electric Motor Drives, IEEE Journal of Emerging and Selected Topics in Power Electronics, Vol. 2, No. 2, June 2014, pp. 129-131.

[6] H.-M. Ryu, J.-W. Kim and S.-K. Sul Synchronous Frame Current Control of Multi-Phase Synchronous Motor, Part I. Modeling and Current Control Based on Multiple d-q Spaces Concept Under Balanced Condition, Conference Record of the 39th IAS IEEE Annual Meeting, Industry Applications Conference, 2004 3-7 Oct. 2004, Seattle, USA, pp. 56-63

[7] Harnefors, L. Pietilainen, K. Gertmar, L. Torque-maximizing fieldweakening control: design, analysis, and parameter selection, Industrial Electronics, IEEE Transactions on , vol.48, no.1, pp.161,168, Feb 2001

[8] X. Kestelyn and E. Semail, A Vectorial Approach for Generation of Optimal Current References for Multiphase Permanent-Magnet Synchronous Machines in Real Time, IEEE Transactions on Industrial Electronics, Vol. 58, No. 11, Nov. 2011, pp. 5057-5065

[9] Levi, E.; Dujic, D.; Jones, M.; Grandi, G. Analytical Determination of DC-Bus Utilization Limits in Multiphase VSI Supplied AC Drives, Energy Conversion, IEEE Transactions on, vol.23, no.2, pp.433,443, June 2008

[10] Casadei, D., Dujic, D., Levi, E. Serra, G. Tani, A. Zarri, L. General Modulation Strategy for Seven-Phase Inverters with Independent Control of Multiple Voltage Space Vectors, IEEE Trans. on Industrial Electronics, Vol. 23, No. 2, May 2008, pp.1921-1932.

[11] Parsa, L. Kim, N. Toliyat, H.A. Field Weakening Operation of High Torque Density Five-Phase Permanent Magnet Motor Drives, Proceedings of 2005 IEEE International Conference on Electric Machines and Drives (IEMDC2005), pp. 1507-1512, 2005.

[12] Casadei, D. Mengoni, M. Serra, G. Tani, A. Zarri, L. Parsa, L. Control of a High Torque Density Seven-phase Induction Motor with Fieldweakening Capability, Proceedings of 2010 International Symposium on Industrial Electronics (ISIE2010), pp. 2147-2152, 2010.

[13] Xuelei, S. Xuhui, W. Wei; C. Research on field-weakening control of multiphase permanent magnet synchronous motor, Electrical Machines and Systems (ICEMS), 2011 International Conference on , vol., no., pp.15, 20-23 Aug. 2011 

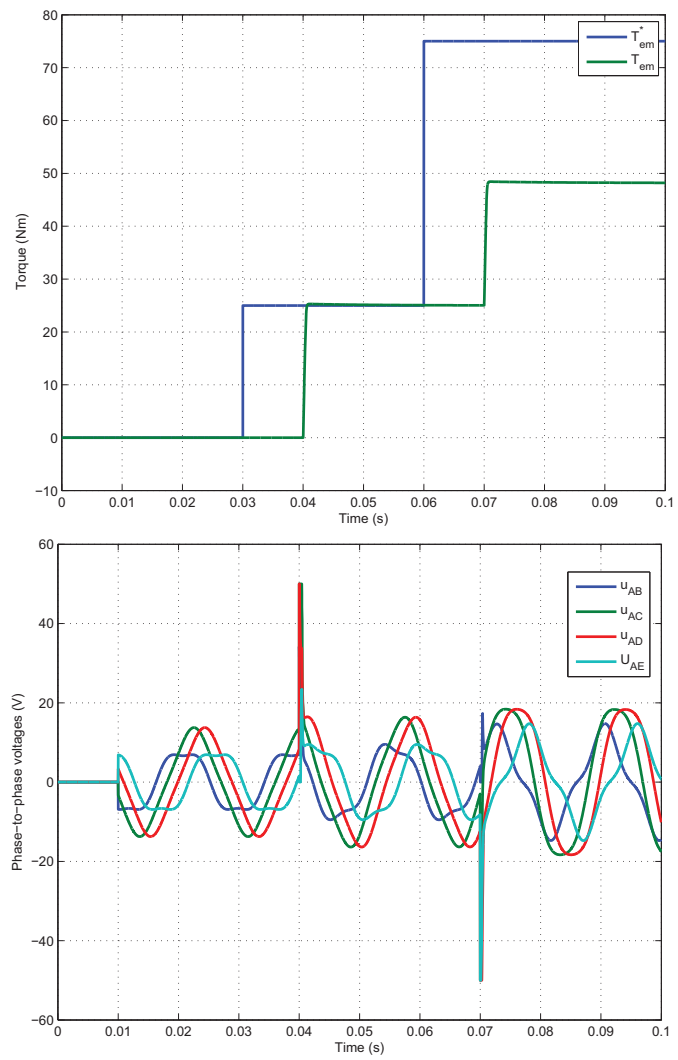
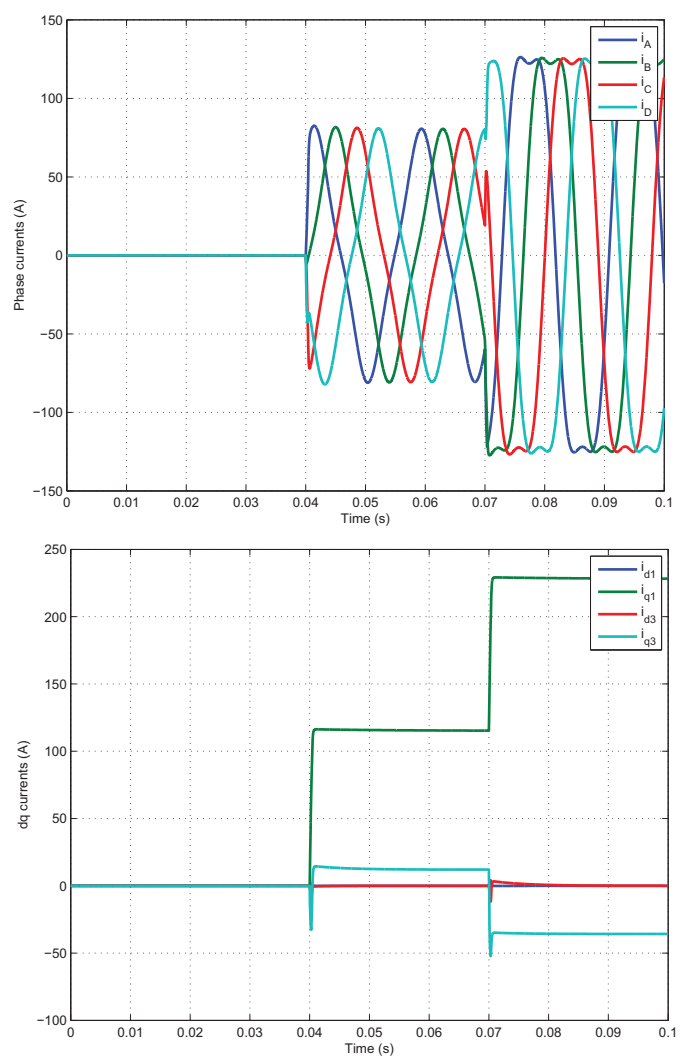

Fig. 2: Simulation results of the first test

[14] J. Rodriguez and P. Cortes, Predictive Control of Power Converters and Electrical Drives. Hoboken, NJ, USA: Wiley, 2012.

[15] Young, H.A.; Perez, M.A.; Rodriguez, J.; Abu-Rub, H., ”Assessing Finite-Control-Set Model Predictive Control: A Comparison with a Linear Current Controller in Two-Level Voltage Source Inverters," Industrial Electronics Magazine, IEEE, vol.8, no.1, pp.44,52, March 2014

[16] C.S. Lim, E.Levi, M.Jones, N.Abd.Rahim, W.P.Hew, FCS-MPC-Based Current Control of a Five-Phase Induction Motor and its Comparison with PI-PWM Control, IEEE Trans. Ind. Electron., vol. 61, no. 1, pp. 149-163, Jan. 2014.

[17] Abdel-Rahim, O.; Funato, H.; Abu-Rub, H.; Ellabban, O., "Multiphase Wind Energy generation with direct matrix converter," Industrial Technology (ICIT), 2014 IEEE International Conference on , vol., no., pp.519,523, Feb. 26 2014-March 12014

[18] X. Kestelyn, E. Semail, and J. P. Hautier, Vectorial multi-machine modeling for a five-phase machine, in Proc. Int. Conf. Electrical Machines (ICEM), Bruges, Belgium, 2002, CD-ROM, Paper 394. 

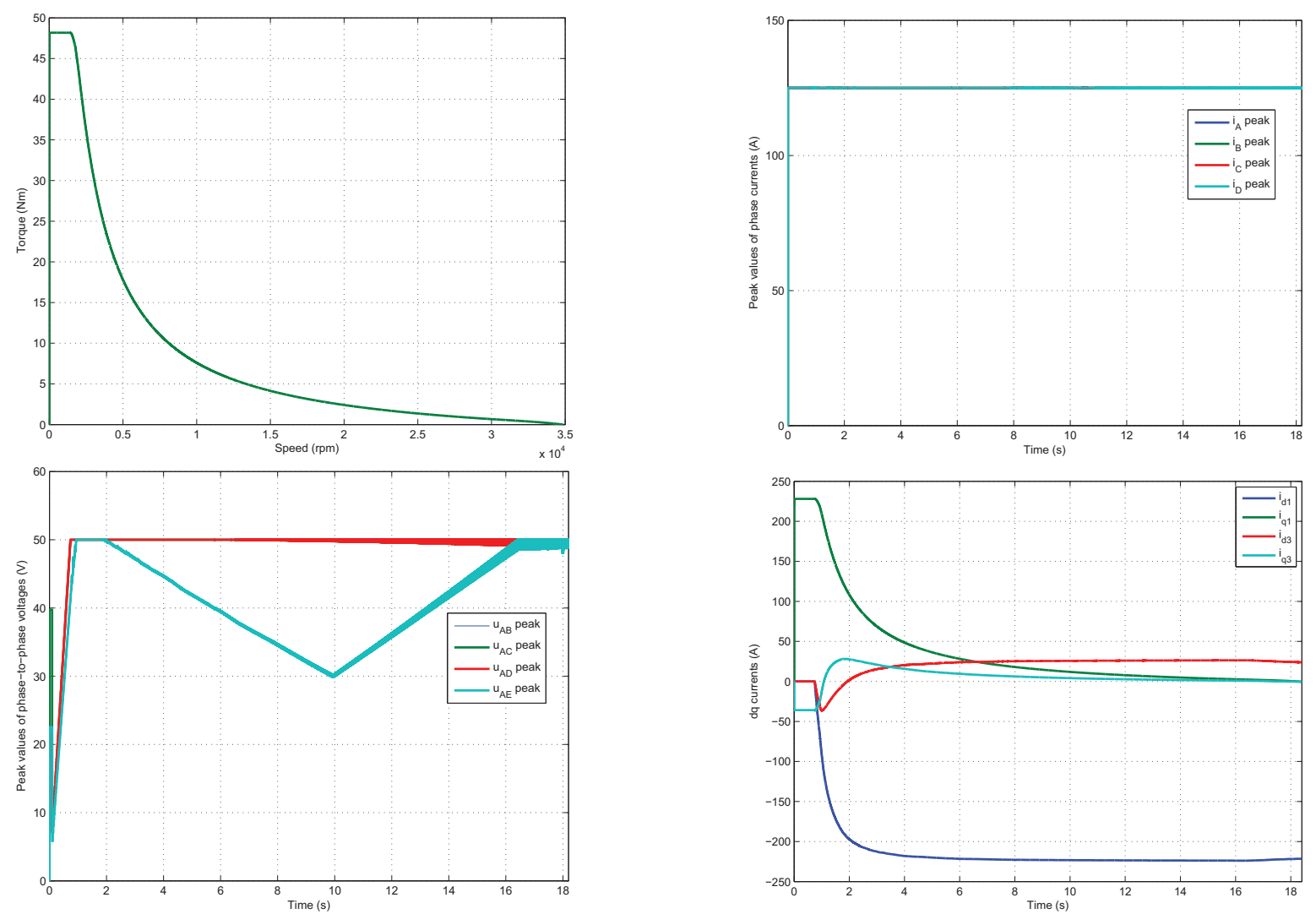

Fig. 3: Simulation results of the second test 